\title{
RANOOMIZED COMPARISON OF ORAL MISOPROSTOL. AND OXYTOCIN IN THE THIRD STAGE OF LABOUR
}

TOTAL OF 10 PAGES ONLY MAY BE XEROXED 


National Library

of Canada

Acquisitions and

Bibliographic Services

395 Wellington Street

Ottawa ON K1A ON4

Canada
Bibliothèque nationale

du Canada

Acquisisitons et

services bibliographiques

395 , rue Wellington

Ottawa ON K1A ON4

Canada
Yourfile Votre référence

ISBN: 0-612-89609-9

Ourfile Notre référence

ISBN: 0-612-89609-9
The author has granted a nonexclusive licence allowing the National Library of Canada to reproduce, loan, distribute or sell copies of this thesis in microform, paper or electronic formats.

The author retains ownership of the copyright in this thesis. Neither the thesis nor substantial extracts from it may be printed or otherwise reproduced without the author's permission.
L'auteur a accordé une licence non exclusive permettant à la Bibliothèque nationale du Canada de reproduire, prêter, distribuer ou vendre des copies de cette thèse sous la forme de microfiche/film, de reproduction sur papier ou sur format électronique.

L'auteur conserve la propriété du droit d'auteur qui protège cette thèse. $\mathrm{Ni}$ la thèse ni des extraits substantiels de celle-ci ne doivent être imprimés ou aturement reproduits sans son autorisation.
In compliance with the Canadian

Privacy Act some supporting forms may have been removed from this dissertation.

While these forms may be included in the document page count, their removal does not represent any loss of content from the dissertation.
Conformément à la loi canadienne sur la protection de la vie privée, quelques formulaires secondaires ont été enlevés de ce manuscrit.

Bien que ces formulaires aient inclus dans la pagination, il n'y aura aucun contenu manquant. 


\title{
Randomized Comparison of Oral Misoprostol and Oxytocin in the Third Stage of Labour
}

Krisztina Bajzak, MD, FRCSC

\author{
A thesis submitted to the \\ School of Graduate Studies in partial fulfillment of the \\ requirements for the degree of \\ Master of Science \\ Memorial University of Newfoundland \\ Faculty of Medicine \\ Department of Obstetrics and Gynecology \\ St. John's, Newfoundland
}

October 1999 


\begin{abstract}
Objective:

To test the null hypothesis that misoprostol, an oral prostaglandin El analog, is not worse than oxytocin intravenous bolus in minimizing blood loss in the third stage of labour.

Method:

One hundred and fifty-six women, having vaginal delivery and at low risk of postpartum hemorrhage, were stratified by oxytocin use in labour and randomly assigned to receive either misoprostol $200 \mu \mathrm{g}$ orally with the anterior shoulder, or oxytocin intravenous bolus after placental delivery, the standard at our institution. Sample size was calculated using a one-tailed $\alpha=0.05$ and a power of $80 \%$, with change in pre-delivery to 1st day postpartum hematocrit as the primary outcome.
\end{abstract}

\title{
Results:
}

Baseline demographic data were similar. There was no significant difference in the change in hematocrit between the misoprostol $(0.046 \%$ packed cell volume[PCV]) and the oxytocin (0.048\% PCV) groups $(\mathrm{P}=0.49)$. More women in the oxytocin stratum received additional oxytocin postpartum $(\mathrm{P}=0.002)$. There were no differences in the frequency of clinical estimate of postpartum blood loss greater than $500 \mathrm{~mL}$, use of other uterotonic agents, manual removal of placenta, dilation and currettage, transfusion, gastrointestinal side effects, or maternal satisfaction. There were no differences in frequency of maternal fever postpartum. After delivery, more women in the misoprostol group strongly preferred to have a medication 
in the form of a pill, rather than an intravenous injection, at the time of delivery of their baby ( $82.8 \%$ versus $42.2 \%, \mathrm{P}<0.00001$, Mann Whitney test)

\section{Conclusions:}

Oral misoprostol is a safe and effective option to minimize blood loss in the third stage of labour, for women at low risk of postpartum hemorrhage. 


\section{DEDICATION}

This is dedicated to Dr. David Young. He has been an inspiration in innumerable ways and the yardstick against which so many of us have measured ourselves.

\section{ACKNOWLEDGEMENTS}

I would like to thank supervisors Dr. J Crane, Dr. D Young and Dr. J Harnett. Thanks also to Donna Hutchens, BN (the research nurse), Dr. P. Parfrey, Dr. S. Pugh, Dr. B. Barbrick, and the attending physicians, residents, nurses, and other staff of the Grace General Hospital in St. John's, Newfoundland, who supported this study.

This study would not have been possible without the women who agreed to participate. Theirs was the greatest of all contributions.

Finally, I would like to thank my family and friends who always understand and support me when work has to come first.

This study was presented at the SOGC $55^{\text {th }}$ Annual Clinical Meeting on June $28^{\text {th }}$, 1999. The oral presentation was awarded first place in the category of Junior Member Obstetrics. The study has also been submitted for publication. 


\section{TABLE OF CONTENTS}

Page

Abstract

Acknowledgments

List of Tables and Figures

List of Abbreviations and Symbols

List of Appendices ii

iv

viii

ix

$\mathrm{x}$ 
Chapter 1 - Introduction

Chapter 2-Background 3

2.1 Background $\quad 3$

2.2 Prostaglandinș 6

$\begin{array}{ll}\text { 2.2.1 Prostaglandins in Obstetrics } & 6\end{array}$

2.2.2 Prostaglandins and Postpartum Hemorrhage 9

$\begin{array}{ll}\text { 2.2.3 Misoprostol } & 11\end{array}$

2.2.4 Misoprostol and Postpartum Hemorrhage Publications $\quad 12$

$\begin{array}{ll}2.3 \text { Significance } & 15\end{array}$

$\begin{array}{ll}\text { Chapter 3-Methodology } & 17\end{array}$

$\begin{array}{ll}\text { 3.1 Standard Management of the Third Stage } & 17\end{array}$

$\begin{array}{ll}3.2 \text { Purpose } & 18\end{array}$

$\begin{array}{ll}3.3 \text { Primary Outcome Measure } & 19\end{array}$

3.4 Sample Size Calculation $\quad 20$

3.5 Secondary Outcome Measures $\quad 22$

3.6 Study Design $\quad 24$

3.7 Subject Eligibility $\quad 25$

3.8 Study Intervention $\quad 26$

3.9 Description of Study Institution $\quad 28$

3.10 Ethics and Consent $\quad 29$ 
3.11 Patient Recruitment $\quad 30$

3.12 Randomization $\quad 32$

3.13 Data

Chapter 4-Results

4.1 Primary and Secondary Outcomes 38

$\begin{array}{ll}\text { Chapter 5 - Discussion } & 42\end{array}$

5.1 Discussion of Results $\quad 42$

$\begin{array}{ll}\text { 5.2 Problems } & 46\end{array}$

$\begin{array}{ll}\text { 5.3 Strengths and Weaknesses } & 47\end{array}$

$\begin{array}{lr}5.3 .1 \text { Validity } & 47\end{array}$

5.3.2 Applicability $\quad 49$

5.4 Conclusions $\quad 50$

References

Appendices $\quad 56$ 


\section{LIST OF TABLES AND FIGURES}

Figure 1.1 Algorithm for PPH Management 2

Figure 1.2 Structure of Prostaglandins of the E and F Series and Some Analogues in Current Use 6

$\begin{array}{lll}\text { Figure } 3.1 & \text { Sample Size Calculation } & 21\end{array}$

$\begin{array}{lll}\text { Figure 3.1a Delta } & 21\end{array}$

$\begin{array}{lll}\text { Figure 3.1b Sample size } & 21\end{array}$

Figure 4.1 Flow diagram of subject assignment 35

$\begin{array}{lll}\text { Table 4.1a Demographic characteristics } & 36\end{array}$

$\begin{array}{lll}\text { Table 4.1b Puerperal characteristics } & 37\end{array}$

$\begin{array}{lll}\text { Table } 4.2 & \text { Postpartum data } & 39\end{array}$

$\begin{array}{lll}\text { Table } 4.3 & \text { Side effects } & 40\end{array}$

Table $4.4 \quad$ Temperature $\geq 37.5^{\circ} \mathrm{C} \quad 41$ 


\section{LIST OF ABBREVIATIONS AND SYMBOLS}

PCV-packed cell volume

SOGC-Society of Obstetricians and Gynecologists of Canada

ACOG- American College of Obstetricians and Gynecologists

PPH- postpartum hemorrhage

Hct. - hematocrit

NSAID- non-steroidal anti-inflammatory

HELLP- hemolysis, elevated liver enzymes, low platelets

NVD- normal vaginal delivery

CI- confidence interval 


\section{APPENDICES}

Appendix A Risk Factors for Postpartum Hemorrhage 56

$\begin{array}{llr}\text { Appendix B Physician Survey } & 58\end{array}$

$\begin{array}{ll}\text { Appendix C Labour Agentry Scale } & 60\end{array}$

$\begin{array}{lll}\text { Appendix D Consent Form } & 68\end{array}$

$\begin{array}{lll}\text { Appendix E Information Sheet } & 71\end{array}$

Appendix F Data Collection Sheet $\quad 74$ 


\section{Chapter 1: INTRODUCTION}

Postpartum hemorrhage refers to excessive blood loss after delivery. Early postpartum hemorrhage occurs within the first 24 hours after birth, and has classically been defined as an estimated blood loss of $500 \mathrm{~mL}$ or greater in this time period (1). Hemorrhage, infection, and hypertension form the "lethal triad" of obstetrics, being collectively responsible for the majority of direct obstetric maternal deaths (2).

Early postpartum hemorrhage has a limited number of etiologies, including lower genital tract lacerations, retained products of conception and abnormalities of placentation, uterine rupture or inversion, and coagulopathy. However, the most common cause of early postpartum hemorrhage is uterine atony (1).

Patients who have had a previous postpartum hemorrhage due to atony have a recurrence risk of $25 \%$ (3). There are other risk factors for PPH (Appendix A). However, most women who have PPH have no identifiable risk factors, so, this potentially catastrophic complication can occur with little or no warning. Therefore, algorithms for management of PPH have been developed (Figure 1.1)(4). If conservative management fails, operative intervention, pelvic vessel embolization or ligation, and hysterectomy may be necessary. 
Figure 1.1 MANAGEMENT OF POSTPARTUM HEMORRHAGE

This management should be instinctive following logical steps.

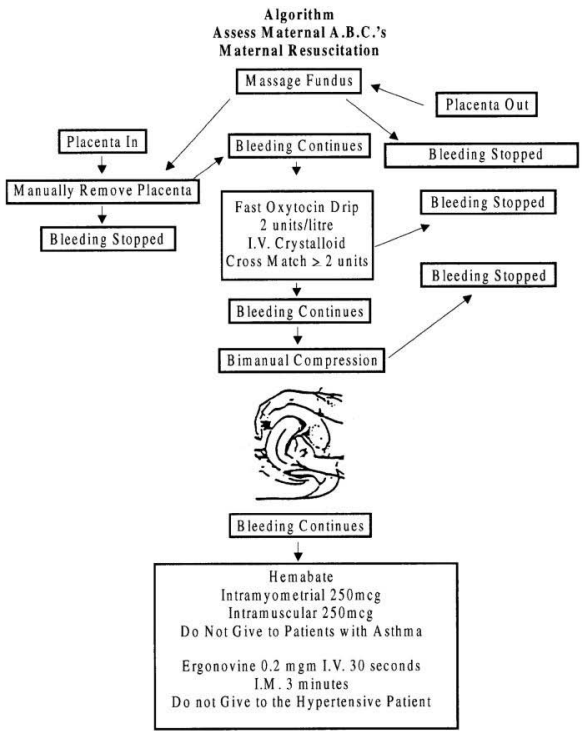

After placenta removed-as soon as you can see, inspect the cervix and vagina for lacerations. Make sure they are sutured. 


\section{Chapter 2: BACKGROUND}

\subsection{Background}

Globally, hemorrhage is still a main cause of maternal mortality. One third of maternal deaths that occur from hemorrhage are due to postpartum hemorrhage (3). In developed countries the incidence is in the range of $2-11 \%$ of deliveries (5). The incidence can be much higher in developing countries. This difference is due, in part, to active versus physiologic management of the third stage of labour. Physiologic management is the routine in developing countries. This involves avoidance of umbilical cord clamping until placental delivery or if the cord is cut prior to placental delivery the blood is allowed to drain from the placenta immediately. The woman assumes a posture that will allow gravity to assist in placental delivery. She then pushes with uterine contractions to deliver the placenta. The baby is placed to the breast to cause a physiologic release of oxytocin (5). Active management of the third stage generally involves the prophylactic administration of a uterotonic agent once the anterior shoulder is delivered or immediately after delivery. The umbilical cord is clamped within 30 seconds of delivery. Controlled cord traction is applied once signs of placental separation are evident and uterine massage continues after placental delivery until blood loss begins to decrease (1). Active management of the third stage reduces the incidence of postpartum hemorrhage by $40 \%$ (5). Physiologic management is routine management of the third stage in developing countries as oxytocics are unstable in warm temperatures and refrigeration is not widely available. Most also require sterile equipment and trained personnel for administration. The majority of women deliver at home where they may be assisted by traditional birth attendants, without access to medical facilities. 
In developed countries, where maternal mortality rates are low, the degree of medical intervention into the physiologic process of the third stage began to be questioned. The "Bristol third stage trial" was carried out to determine if active management was justified in the controlled setting of a British maternity hospital. One thousand six hundred and ninety-five women were randomly allocated to active or physiologic management of the third stage of labour with estimated blood loss of $500 \mathrm{~mL}$ or greater was the primary outcome measure. Although the sample size was calculated to be 3900 women, the rate of postpartum hemorrhage was so much greater in the physiologic group, $17.9 \%$ versus $5.9 \%$ in the active management group, that interim analysis resulted in early termination of the study (5).

In selecting a uterotonic agent effectiveness, safety, route of administration, stability, and cost are all considerations. Ergot alkaloids were the first effective agents used for the treatment of postpartum hemorrhage, thereby dramatically reducing maternal mortality. Their onset of action is delayed for 4-5 minutes after administration, but their effects last for several hours. They are vasoconstrictors, with side effects including nausea, vomiting, headache, hypertension, and occasional reports of seizure, cardiac arrest and cerebral hemorrhage (6). It is because of these side effects that they are relatively contra-indicated in patients with hypertension, and that other uterotonic agents have been sought. Administration is parenteral or by an oral tablet. Ergometrine must be refrigerated and protected from light. Thus improper storage can lead to loss of potency, especially problematic in developing counties.

Oxytocin analogs were the next proven effective agents to be used. Administered parenterally, the onset of action is as rapid as 30 seconds, but more transient. Intravenous 
oxytocin causes vasodilation, and side effects including hypotension, nausea and vomiting (7). A combination of these two medications is also used, Syntometrine®, administered intramuscularly, consisting of oxytocin 5 units and Ergometrine $0.5 \mathrm{mg}$, to yield a rapid onset, but prolonged duration of action. Side effects are hypertension and its associated complications (8). 


\subsection{Prostaglandins}

\subsubsection{Prostaglandins in Obstetrics}

Prostaglandins are physiologic substances with widespread functions throughout the body. Like other eicosanoids, they are derived from arachadonic acid. Products of the cyclo-oxygenase pathway, prostaglandins' chemical structure is that of a substituted pentane ring with attached fatty acid moieties at two adjacent carbons (Figure 1.2)(9).

\section{SOME ANALOGUES IN CURRENT USE}

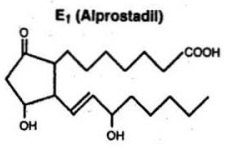

$E_{2}$ (Dinoprostone)<smiles>CCCCCC(O)/C=C/C1C(O)CC(=O)C1CC=CCCCC(=O)O</smiles><smiles>CCCCC(O)(CCCCCOC)CCCCC1C(=O)CC(O)C1C=CCCCOC(C)(C)C</smiles><smiles>CCCCCC(O)/C=C/C1C(O)CC(O)C1CCCCCCC(=O)O</smiles><smiles>CCCCCC(O)/C=C/C1C(O)CC(O)C1CC=CCCCC(=O)O</smiles>

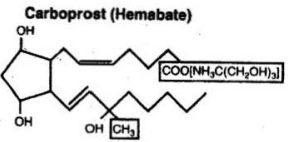


Prostaglandins are named by letter classes (A, B, D, E and I) denoting differing structure of the pentane ring and numeric designation indicating the number of double bonds in the fatty acid moieties (9). Production of prostaglandins is regulated by substrate availability, dependent upon phospholipase mediated release of arachadonic acid release from cell membrane stores, and cyclo-oxygenase, also known as prostaglandin $\mathrm{G} / \mathrm{H}$ synthase. Metabolism is achieved by beta and omega oxidation of the fatty acid. Receptors, present in the cell membrane and intracellular organelles, are specific for the pentane ring and not the fatty acid structure. Therefore, synthetic products have been produced which have similar effects but are resistant to metabolism (Figure 1.2)(9).

Prostaglandins are intimately involved with both pregnancy maintenance and labour and delivery. Found in the amniotic fluid, prostaglandin levels increase approaching term and increase further with the onset of labour. Prostaglandin F2 $\alpha$ is produced by the maternal decidua and regulates myometrial activity. Action on the myometrium is dependent upon the presence of prostaglandin receptors, of which there are four isoforms. Two of these receptor isoforms promote uterine muscle relaxation and two promote uterine muscle contraction (10).

Prostaglandin E2 is produced by the amnion and plays a critical role in cervical ripening, essential for labour progression. In the cervix, prostaglandin E2 causes vasodilation and increased vascular permeability. This facilitates neutrophil invasion, the source of collagenase, which causes collagen degradation and cervical softening (10).

Both prostaglandin $\mathrm{E}$ and $\mathrm{F}$ stimulate myometrial contractility and prostaglandin receptors are present throughout gestation (9). Therefore, they have various applications in obstetrics and gynecology as stimulants of uterine contraction. They have been 
investigated in this capacity since the 1960 's and have become established agents for first and second trimester pregnancy termination, cervical ripening and induction of labour, and treatment of postpartum hemorrhage. 


\subsubsection{Prostaglandins and Postpartum Hemorrhage}

Both prostaglandin $\mathrm{E} 2$ and $\mathrm{F} 2 \alpha$ analogs have been investigated in the treatment of refractory postpartum hemorrhage. Prostaglandin E2 has primarily been used as an intravenous infusion. Although effective, side effects include nausea, vomiting, diarrhea, uterine hypertonus, tachycardia, increased stroke volume, and a decrease in peripheral vascular resistance (11), occasionally leading to significant hypotension (12). There have also been occasional reports of severe hypertension (13) secondary to arterial spasm. Analogs of prostaglandin E2 have also been administered directly to the uterine cavity via Foley catheter or suppository, although this is uncommon.

Analogs of prostaglandin $\mathrm{F} 2 \alpha$ have also been investigated. Routes of administration include intravenous, intramuscular, and intramyometrial. The 15-methyl analog, Hemabate $\circledast$, administered intramuscularly, has been widely used, and has become front line medical therapy for PPH. Hemabate is successful $85-95 \%$ of the time (14), and its failure most often indicates a cause for hemorrhage other than uterine atony (15). The rate of side effects of nausea, vomiting and diarthea is approximately $10 \%$ (15). Other side effects include hypertension, headache, flushing, and a transient mild hyperthermia (11). Heart rate and cardiac output increase, but there is no change in systemic vascular resistance (16). A significant side effect of bronchospasm contraindicates its use in asthmatics. A less recognized complication of arterial oxygen desaturation in normal healthy women is not uncommon. This is due both to an increase in pulmonary vascular resistance and bronchospasm leading to pulmonary shunting (17).

Thus, prostaglandins previously used in obstetrics have potentially significant morbidity. They also require refrigeration or parenteral administration and are expensive. 
At the commencement of this study, no trials investigating misoprostol for postpartum hemorrhage prevention had been reported. Seven trials were published describing the prophylactic use of a prostaglandin in the third stage (18-24). Five studies investigated a prostaglandin F2 $\alpha$ analog and two studied a prostaglandin E2 derivative. Three of these studies had small sample sizes (19-21), one amalgamated randomized and nonrandomized study groups (22) and another had no sample size calculation with a result of no significant difference between treatment and control groups (24). All studies found the prostaglandin to be as effective, if not more effective than the standard uterotonic to which it was compared. 


\subsubsection{Misoprostol}

Misoprostol (Cytotec, Searle) is a synthetic methyl ester of prostaglandin El with a proven uterotonic effect in controlled studies, including published data from our own center (25). It is marketed for prevention and treatment of NSAID induced gastric and duodenal ulcers at a dose of $800 \mu \mathrm{g}$ per day. Its uterine effect is mediated by selective binding to $\mathrm{EP}_{2} / \mathrm{EP}_{3}$ prostanoid receptors (26). It is rapidly absorbed after oral administration, detectable in the circulation within two minutes, with a Tmax of thirty minutes. Misoprostol is rapidly metabolized, by most body tissues, into inactive metabolites, and therefore not contra-indicated in patients with hepatic or renal dysfunction, although caution is still advised in the product monograph. Other cautions are based primarily on reports of injectable prostaglandins and relate to epilepsy and cardiovascular conditions where hypotension may pose a specific problem, such as coronary artery disease. Primary reported side effects of misoprostol are diarrhea, nausea, and abdominal discomfort. These appear to be dose dependent. 


\subsubsection{Misoprostol and Postpartum Hemorrhage Publications}

Since this study began, there have been other investigations published of misoprostol use in the prevention of postpartum hemorrhage. El-Refaey et al. published two prospective observational reports of $600 \mu \mathrm{g}$ of oral misoprostol given after umbilical cord clamping $(27,28)$. In the initial report on 100 women, six had and estimated blood loss of greater than or equal to $500 \mathrm{~mL}$. None had an estimated blood loss of $1000 \mathrm{~mL}$ or more. Subsequent to misoprostol, oxytocin was administered to six women and a blood transfusion to one. They reported shivering to be a significant side effect, affecting sixtyeight percent. The $6 \%$ rate of postpartum hemorrhage was considered comparable to historical results of Syntometrine $®$. In the second report by this group, 237 women were observed. Estimated blood loss greater than or equal to $500 \mathrm{~mL}$ was, once again, six percent with no women having an estimated blood loss greater than or equal to $1000 \mathrm{~mL}$. Subsequent oxytocin was administered to $5 \%$, transfusion to two women and shivering reported in $62 \%$. They also observed a $0.5^{\circ} \mathrm{C}$ temperature increase after misoprostol administration. They concluded that the rate of postpartum hemorrhage was better than that reported for physiologic management of the third stage and comparable to that reported for Syntometrine ${ }^{\circledR}$.

There have been two reports of randomized trials of rectal misoprostol, $400 \mu \mathrm{g}$, for postpartum hemorrhage prevention $(29,30)$. The first trial was a prospective, unblinded comparison of misoprostol in 241 women with one ampoule of Syntometrine $\mathbb{B}$, intramuscularly, in 250 . The primary outcome measure was estimated postpartum blood loss of $500 \mathrm{~mL}$ or greater. This study had problems with its randomization protocol. 
Women who developed hypertension in labour after allocation to the Syntometrine $(8)$ group only, were excluded and the allocation to the Syntometrine $\otimes$ group reassigned to other participants. After analysis of the data based upon the medication that the women actually received, the data was reanalyzed after excluding all women in both groups with hypertension in labour, a total of 84 , yielding "similar results". With respect to the primary outcome measure, information was available on 231 women in the misoprostol group and 233 in the Syntometrine ${ }^{\circledR}$ group. The incidence of postpartum hemorrhage was low in both groups, $0.9 \%$ and $0.4 \%$ respectively. They found no difference in rates of postpartum hemorrhage between groups, but concluded their sample size was insufficient for this comparison. In the second study by this group, $400 \mu \mathrm{g}$ of rectal misoprostol given to 271 women was compared with non-identical placebo given to 275 . Measure of collected blood loss equal to or greater than $1000 \mathrm{~mL}$ was the primary outcome. This study did report a sample size calculation and computer generated random allocation. They found no difference in rates of postpartum hemorrhage, $4.8 \%$ and $7 \%$ respectively, although they were at risk for type II error, as the rate of postpartum hemorrhage in their control group was not as high as that estimated in their sample size calculation. Shivering, with an overall incidence of $7.1 \%$ measured on the final 70 women enrolled, was not a significant side effect.

Finally, Hofmeyr et al. published a comparison of oral misoprostol, $400 \mu \mathrm{g}$ with non-identical placebo in 250 women per group (31). Measure of collected blood loss equal to or greater than $1000 \mathrm{~mL}$ was the primary outcome. This study reported a sample size calculation and computer generated random allocation. They found no significant 
difference in postpartum hemorrhage, but significantly less subsequent oxytocic use in the misoprostol group. This trial was also at risk for type II error for the same reason as the previous trial. They found shivering to be more common in the misoprostol group, with a rate of $19 \%$ versus $5 \%$ in the placebo group. Thus, there still has not been a welldesigned randomized comparison of oral misoprostol with a standard uterotonic for prevention of postpartum hemorrhage.

In 1998, O'Brien et al. reported the use of rectal misoprostol, $1000 \mu \mathrm{g}$ in 14 women, for the treatment of postpartum hemorrhage. Eligible women were those clinically diagnosed with postpartum hemorrhage, unresponsive to oxytocin and ergometrine, or ergometrine was contra-indicated. While waiting for carboprost (Hemabate), the standard treatment, to become available, misoprostol was given. In all 14 patients hemorrhage was controlled prior to the availability of carboprost (32). 


\subsection{Significance}

Misoprostol offers several advantages over the currently available uterotonics. It requires no refrigeration or protection from light. No sterile equipment is required for administration. It is inexpensive, and has relatively few side effects. These characteristics make it ideal for use in developing countries where the incidence of postpartum hemornhage can be the highest. During preparation for this study a prospective observational study was published using misoprostol for prophylaxis against postpartum hemorrhage in the third stage, in 237 patients (27). Their conclusions were that the rates of postpartum hemorrhage, need for further oxytocics, and length of the third stage were decreased when compared with historical results of physiologic

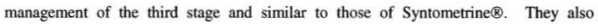
concluded that side effects associated with misoprostol were less, and they felt that a double blind, randomized, controlled trial was urgently needed.

If misoprostol can be shown to be effective in minimizing blood loss in the third stage of labour, in a low risk setting, further study of its use in treatment of postpartum hemorrhage would be appropriate. If misoprostol is proven to be effective in the prevention and treatment of postpartum hemorrhage, there is a potential to reduce maternal mortality globally.

Of increasing importance in developed countries, where maternal mortality is low, is the quality of the birth experience. This is evidenced by changes in birthing rooms to reflect the more comfortable atmosphere of a private room, with medical equipment hidden out of eyesight until and if needed. Similarly, there has been a recent surge in the popularity of midwifery in North America. In developed countries, women have become 
powerful advocates on their own behalf to obtain these apparent luxuries. In the medical profession, where a physician is often concerned with preventing mortality, the importance to the patient of these elements of the birth experience can be underestimated. The availability of an oral tablet, as an alternative to an intravenous injection for the purpose of PPH prevention for women who have not required an IV in labour, may be an additional element to improve the birth experience. 


\section{Chapter 3: METHODOLOGY}

\subsection{Standard Management of the Third Stage}

In our center, the standard management of the third stage depends upon the preference of the attending physician. However, there is relatively little variation. An intravenous bolus of oxytocin immediately after delivery of the placenta is customary. The dose is 5 or 10 units. Occasionally this will be given prior to delivery of the placenta once delivery of the fetus' anterior shoulder is visualized. The advantage of this would be to cause a uterine contraction, which would hasten the delivery of the placenta, shorten the third stage, and therefore decrease blood loss. A theoretical disadvantage of this practice is the question of whether this increases the risk of a retained placenta, which prolongs the third stage, leading to increased risk of PPH (9). There are studies, which demonstrate each side of the argument, but the majority of studies demonstrate no increase in incidence of retained placenta $(6,33,34)$. It remains the current practice of the majority of physicians at our center to administer 5 units oxytocin after placental delivery. The umbilical cord is clamped immediately after delivery and controlled cord traction is applied after signs of placental separation occur. 


\subsection{Purpose}

The original intention of this study was to compare misoprostol to oxytocin with frequency of postpartum hemorrhage as the primary outcome measure. A chart review of 50 normal vaginal deliveries revealed the rate of postpartum hemorrhage to be less than 1

percent. With this low incidence and a birthrate in our center of approximately 2400 deliveries per year, the study would not have been feasible. An alternative outcome measure of a clinically significant blood loss, but less than $500 \mathrm{~mL}$, was chosen. A survey of eight locally practicing obstetricians was conducted (Appendix B) to obtain a measure of clinically significant difference in blood loss, reflected by a change in hematocrit, between treatment and control groups. It was decided that the information obtained from this study, which was expected to demonstrate the safety and efficacy of misoprostol in minimizing postpartum blood loss in a controlled setting of low risk patients, would be valuable as preliminary work to support further investigation of misoprostol for PPH prevention and treatment. 


\subsection{Primary Outcome Measure}

When studying postpartum blood loss, measuring it accurately and objectively is difficult. Postpartum hemorrhage has classically been defined as clinically estimated blood loss greater than $500 \mathrm{~mL}$ within the first 24 hours of a vaginal delivery. It is well documented that clinical judgment underestimates the actual blood lost by approximately 50 percent. However, meticulous collection of postpartum blood loss is tedious, and also subject to error. ACOG has indicated that a drop in hematocrit of 0.10 be used as a more objective definition of postpartum hemorrhage (35). 


\subsection{Sample Size Calculation}

A chart review of fifty normal vaginal deliveries revealed an average drop in hematocrit of 0.03 and a standard deviation of 0.03 . The survey conducted of the locally practicing obstetricians yielded a clinically significant drop in hematocrit of 0.042 . Selecting drop in hematocrit as the primary outcome measure is particularly appropriate to reduce bias in this study, as the study is not blinded. Oxytocin 5 or 10 units given intravenously was chosen as the standard, as it is the customary uterotonic agent given, at the discretion of the attending physician, at our center. The sample size was calculated using a one-tailed $\alpha=0.05, \beta=0.20, \Delta=0.012$, and $\sigma=0.03$, using the formula to compare means of two independent groups (Figure 3.1). Given the advantages of oral misoprostol, it would be considered an acceptable alternative if proven to be as good as, or better than oxytocin. Therefore, a one-tailed $\alpha$ was chosen to demonstrate that misoprostol is as good as or better than oxytocin in minimizing blood loss in the third stage of labour. 
Figure 3.1: Sample size calculation

Figure 3.1a: Delta

$$
\begin{aligned}
\text { Delta } & =\text { clinically significant Hct. drop }- \text { mean Hct. drop } \\
& =0.042-0.003 \\
& =0.012
\end{aligned}
$$

Figure 3.1b: Sample size

$$
\begin{aligned}
\text { N/group } & =2\left[(\text { Zalpha }+ \text { Zbeta })^{2} \text { sigma }^{2} / \text { delta }^{2}\right] \\
& =2\left[(1.65+0.84)^{2}(0.03)^{2} /(0.012)^{2}\right] \\
& =77.5 \\
& =78
\end{aligned}
$$




\subsection{Secondary Outcome Measures}

Important secondary outcome measures fell into one of a number of categories.

I. Other blood loss indicators:

EBL greater than $500 \mathrm{~mL}$

Clinically significant anemia ( $\mathrm{Hb}$. Less than $100 \mathrm{~g} / \mathrm{L}$ )

Transfusion therapy

Het. fall $>0.10$

II. Third stage variables related to postpartum blood loss:

Length of the third stage

Retained placenta

III. Other interventions for excessive blood loss:

a. Medical

Further oxytocin as intravenous bolus or infusion

Administration of carboprost

Administration of ergonovine

b. Surgical

Manual placental removal

Dilation and curettage

Laparotomy

Hysterectomy 
IV. Side Effects:

Nausea

Vomiting

Pyrexia

v. Patient Satisfaction:

Modified Labor Agentry Scale (Appendix C)

Postpartum fever was added as a secondary outcome based upon a report of pyrexia with misoprostol use in this setting, published after the study had already begun (27). 


\subsection{Study Design}

A prospective blinded randomized trial would be the optimal study design to answer the research question being posed that is to best establish cause and effect. An assessment of the cost of placebo was obtained. An application for funding was submitted to the Association of Professors in Obstetrics and Gynecology, but was declined. The company manufacturing misoprostol had previously been approached regarding the initially proposed third stage study and had declined sponsorship. Therefore, no funding for a placebo controlled trial could be found. Although the study could not be blinded, it was felt that having an objective primary outcome measure would reduce the potential bias. However, many of the secondary outcomes were subjective. 


\subsection{Subject Eligibility}

Subjects under the age of 19 years old were excluded, as required by the ethics committee at our centre. Patients with risk factors for PPH were also excluded [i.e. multifetal gestation, hydramnios, HELLP syndrome, known coagulation abnormalities, grand multiparas (women delivering their fifth child), women with a previous PPH, placenta previa, cesarean delivery, precipitous labour (less than three hours), chorioamnionitis, and women with anemia $(\mathrm{Hb},<90 \mathrm{~g} / \mathrm{L})$. Augmentation with oxytocin in labour is a risk factor for PPH because it generally is associated with a prolonged labour. However, many studies investigating PPH have found no increase in the incidence of PPH in this group of patients $(8,34,36,37)$. Induction with oxytocin is generally followed by continued augmentation with oxytocin. Oxytocin augmentation in labour is such a common occurrence that excluding this population of patients would affect the generalizability of the results. Therefore, it was decided that it was reasonable not to exclude women based upon this criterion. But because oxytocin augmentation in labour is generally considered a predisposing factor for increased postpartum blood loss, a pre-randomization stratification was conducted for patients with this intervention. All patients who did not meet exclusion criteria and presented in labour were considered eligible. 


\subsection{Study Intervention}

The dose of misoprostol was chosen before reports of misoprostol given for this purpose had been published. Induction of labour with misoprostol had been carried out in our center in a research setting. The dose for induction was $50 \mu \mathrm{g}$ at a dosing interval of four hours. There had been some concern regarding uterine hyperstimulation with this regimen, leading to investigation of optimal dose and dosing interval, which is currently being conducted. Second trimester terminations have also been investigated at our center using misoprostol. Since hyperstimulation is not a concern in this setting and labour is more difficult to induce, a higher dose of $200 \mu \mathrm{g}$ is used and is effective. Based upon this experience of the uterine stimulation obtained with these regimens, an arbitrary dose of $200 \mu \mathrm{g}$ was chosen.

A maternal blood sample for hematocrit and hemoglobin was obtained prior to delivery, the custom in our center. The woman was randomized to receive either misoprostol $200 \mu \mathrm{g}$ orally with delivery of the anterior shoulder, or pitocin five or ten units (based on attending physician preference) intravenously after placental delivery. In both groups controlled cord traction was considered appropriate when signs of placental separation were evident. After receiving misoprostol, patients in the study group were not treated differently with respect to management of the third stage of labour. If, in the opinion of the attending physician, the participant experienced excessive blood loss, the physician was free to intervene according to their customary management plan, including administering intravenous oxytocin as a bolus or infusion, or further medications as deemed necessary. Women who received oxytocin in labour, customarily have an 
infusion continued postpartum. This standard management was also carried out in the study group. Women were then followed, as per routine, with regular visual assessment of blood loss and palpation of uterine tone, by the attending nursing staff. If a participant experienced excessive blood loss or had a "boggy" uterus, a physician was notified, and took necessary measures after patient assessment. A record was made of further actions required based on clinical estimation of excessive blood loss. A second blood sample for maternal hematocrit and hemoglobin was obtained 24 hours $(+/-6$ hours) postpartum. Subject satisfaction was assessed by a modified Labour Agentry Scale, administered postpartum but prior to hospital discharge (Appendix C). 


\subsection{Description of Study Institution}

The study was conducted at the Grace General Hospital, St. John's Newfoundland, from October 13, 1997 to January 18, 1999. This center is the tertiary referral center for the province of Newfoundland and Labrador, as well as parts of Quebec. The delivery rate is approximately 2400 per year. Both obstetricians and general practitioners admit and care for patients. Obstetric/gynecology residents, family practice residents, and medical and nursing students participate in patient care. Between approximately $8 \mathrm{am}$ and $5 \mathrm{pm}$ consultants and general practitioners care for their own inpatients. Family practice physicians arrange for "on call" coverage of patient care within their practices. A single specialist obstetrician/gynecologist provides "on call" coverage for their patients and family practice consults. A resident, intern, and medical student also provide "on call" coverage. There are no independently practicing midwives in the hospital. Nursing staff support patients in labour in the caseroom, as well as on the obstetrical ward, in shifts. The patient population is predominantly Caucasian women. No official data on the PPH rate is available. A chart review of 50 normal vaginal deliveries revealed a rate of less than $1 \%$. 


\subsection{Ethics and Consent}

The study was approved by the Human Investigation Committee of the Faculty of Medicine, Memorial University of Newfoundland, and the hospital ethics board. Obstetricians/gynecologists and general practitioners performing deliveries at the Grace General Hospital were contacted in writing. The purpose and design of the study were outlined and a copy of the consent form was included. No physicians refused to allow their patients to be approached for recruitment.

Consent was obtained by the attending resident or staff physician, with a standardized consent form (Appendix D), upon patient admission to the caseroom in labour. This was obtained after the patient and her partner, if available, had an opportunity to review both the information sheet (Appendix E) and consent form. The study was also explained verbally and patients were encouraged to ask questions which were answered to their satisfaction. 


\subsection{Patient Recruitment}

Eligible patients were identified upon admission to the caseroom. This was generally done by the resident working in the caseroom during the day, the investigator, or the "on call" resident. Recognition of eligible patients by the nursing staff was also very important, as the attending resident, busy with their regular work, did not always remember to approach eligible patients for recruitment. In this instance, the nursing staff would supply the patient with an information sheet to read until the resident or attending physician were available to discuss the study with the patient.

The discussion included a summary of the background information, a description of the standard management of the third stage and a description of the proposed study intervention. Risks and benefits of participating were discussed. Patients were informed of the fact that they would receive an additional blood test if they chose to participate. Patients were reassured that their participation was entirely voluntary, and that, should they decline participation, their care would not be compromised in any way. Patients were encouraged to discuss their thoughts privately with their partner, and to verbalize any questions they had. If they appeared to understand well and were agreeable, they were asked to sign the consent form in the presence of the resident or staff with whom they had the discussion, who also signed the consent form.

Given the importance of the team effort for patient recruitment and care during the study, information sessions were held by the investigator with the attending physicians, residents and nursing staff from time to time. The objectives of the study were discussed, as well as the therapeutic intervention and subsequent management (i.e. that it should not in any way be different) of the patient. As the study proceeded, this 
also provided an opportunity for staff to communicate any technical difficulties associated with implementing the study and a forum for discussion on how to overcome these difficulties. These meetings also served as positive reinforcement for the tremendous efforts of the staff and maintained enthusiasm for the study. 


\subsection{Randomization}

Randomization was performed by computer generated random numbers in randomly alternating blocks of four and six (Statistix 4.1, Analytical Software, Tallahassee, Florida). As previously mentioned, there was a pre-randomization stratification for oxytocin use in labour. Cards marked with either "Misoprostol" or "Oxytocin" were placed in sequentially numbered opaque and sealed. Each envelope then had a copy of the information sheet, consent sheet, modified Labour Agentry Scale (38), and data collection sheet attached by paper clip. The envelopes were then placed within file folders and placed in the caseroom.

Once a patient had been identified as being eligible, they were approached for participation. If they consented, then immediately prior to delivery, the women were allocated to study or control group by opening the next envelope in the appropriate stratum, which was performed by the attending resident, staff, or nurse. The contents of the envelope and attachments were then placed in the participant's chart. A record was kept of all women approached. If they declined or if they subsequently met exclusion criteria prior to randomization, this was recorded. If they were randomized, their group allocation was noted. This list was checked on a daily basis and data from randomized patients collected. The remaining envelopes were also checked daily to ensure adequate supply and that no envelopes went missing. 


\subsection{Data}

The data was collected by reviewing the patient chart and recording information on the data collection sheet (Appendix F). The Labour Agentry Scale was also collected from the patient. The data was then entered into the computer database awaiting statistical analysis following study completion. This was performed with the same computer program as the randomization, Stastistix 4.1. Entry of the data was carried out by a research nurse. Regular discussions occurred between the nurse, investigator, and one of the supervisors regarding problems with data entry (i.e. data missing on 24 hour hematocrit, analyzing data on an intent to treat basis, etc.). No speculation on outcomes was discussed. A post hoc analysis of postpartum temperature greater than or equal to $37.5^{\circ} \mathrm{C}$ was performed. This data was obtained retrospectively. 


\section{Chapter 4: RESULTS}

Data were analyzed on an intent to treat basis by parametric (student's t test, chisquare) and non-parametric statistics (Fisher exact, Mann Whitney $\mathbf{U}$ tests) using Statistix 4.1 (Analytical Software, Tallahassee, F1). Significance of the primary outcome was considered at $P<0.05$. The level of significance for all secondary analyses was $\mathrm{P}<0.001$ (by Bonferroni correction).

During the study period 233 women were approached for enrollment. Forty women declined participation and 193 gave consent. Of those consenting, 17 were excluded because of cesarean birth. An additional 3 consenting women were not randomized due to precipitate delivery. One hundred and seventy-three women were randomized, 88 in the oxytocin group and 85 in the misoprostol group. Data for the primary outcome of change in hematocrit was available for 156 women, 80 in the misoprostol group and 76 in the oxytocin group (Figure 4.1). Of the eighteen women who have no data available on postpartum hematocrit change, none were diagnosed clinically with postpartum hemorrhage or received transfusion therapy. Randomization was effective as there were no significant differences between the two groups with regard to maternal and neonatal demographic data (Tables $4.1 \mathrm{a}$ and $4.1 \mathrm{~b}$ ). 


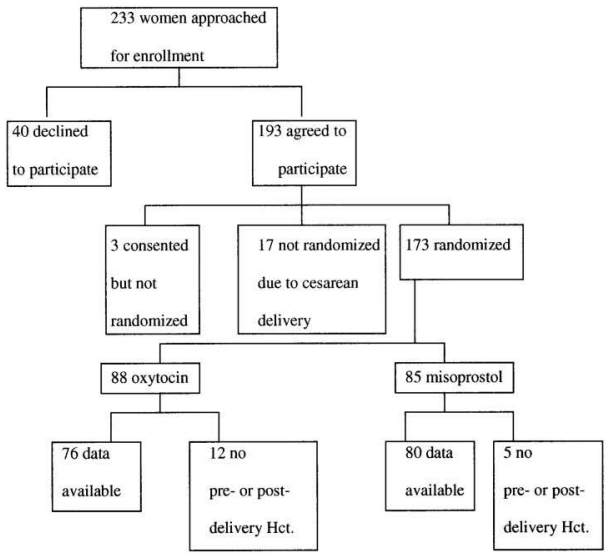

Figure 4.1: Flow diagram of subject assignment 
Table 4.1a.

\begin{tabular}{|l|c|c|c|}
\hline \multicolumn{3}{|l|}{ Demographic Characteristics } \\
\hline & Oxytocin & Misoprostol & P \\
& $\mathbf{n = 7 6}$ & $\mathbf{n = 8 0}$ & \\
\hline Maternal age (y) & $28.4(4.1)$ & $27.6(4.7)$ & $0.27^{*}$ \\
Parity & $0(0,1.0)$ & $1.0(0,1.0)$ & $0.88^{\Omega}$ \\
Nulliparous & 38 & 40 & $1.00^{\circ}$ \\
Antepartum Hct. & $0.37(0.03)$ & $0.37(0.03)$ & $0.70^{*}$ \\
(\%PCV) $^{\gamma}$ & & & \\
Birthweight $(\mathrm{g})^{\gamma}$ & $3569(530)$ & $3517(459)$ & $0.51^{*}$ \\
\hline
\end{tabular}

Data given as number or mean (standard deviation)

${ }^{\Delta}$ Data given as median (25\%, $75 \%$ quartiles)

"Student's t test

-Chi-squared

"Mann Whitney U test 
Table 4.1b.

\begin{tabular}{|c|c|c|c|}
\hline \multicolumn{4}{|l|}{ Puerperal Characteristics } \\
\hline & Oxytocin $n=76^{\gamma}$ & Misoprostol $\mathbf{n}=80^{\gamma}$ & $\mathbf{P}$ \\
\hline Intrapartum oxytocin & 48 & 48 & $0.69^{-1}$ \\
\hline Induction & 22 & 14 & $0.09^{\infty}$ \\
\hline Augmentation & 26 & 34 & $0.29^{\infty}$ \\
\hline Duration Stage I (min) & $426(241)$ & $386(230)$ & $0.29^{*}$ \\
\hline Duration Stage II (min) & $70(62)$ & $68(63)$ & $0.86^{\star}$ \\
\hline Delivery & & & $0.30^{\circ}$ \\
\hline NVD & 59 & 62 & \\
\hline Vacuum & 5 & 10 & \\
\hline Forceps & 12 & 8 & \\
\hline Episiotomy & & & $0.69^{\phi}$ \\
\hline Median & 5 & 3 & \\
\hline Mediolateral & 18 & 21 & \\
\hline Laceration & & & $0.48^{\circ}$ \\
\hline 1st degree & 12 & 17 & \\
\hline 2nd degree & 29 & 24 & \\
\hline 3rd degree & 2 & 5 & \\
\hline Temp $\geq 37.5^{\circ} \mathrm{C}$ in labor & 17 & 23 & $0.75^{4}$ \\
\hline
\end{tabular}

${ }^{\gamma}$ Data given as number or mean (standard deviation)

*Student's $t$ test

${ }^{\infty} \mathrm{Chi}$-squared

${ }^{\circ}$ Fisher exact test 


\subsection{Primary and Secondary Outcomes}

The mean drop in hematocrit 24 hours postpartum, the primary outcome measure, was not significantly different between the two groups (Table 4.2). There were no significant differences in secondary outcomes, including postpartum hemorrhage, anemia, administration of carboprost or ergonovine for excessive bleeding, incidence of transfusion, manual removal of the placenta, and postpartum dilation and curettage. No patients required laparotomy or hysterectomy. There was a trend toward more women in the oxytocin group receiving additional oxytocin (intravenous bolus or infusion)(51/76) compared with the misoprostol group (34/80)( $\mathrm{P}=0.002)$. There was also a trend towards a shorter third stage in the misoprostol group, but this did not reach statistical significance $(\mathrm{P}=0.095)$. There were no differences in nausea and vomiting between the two groups (Table 4.3). There was a trend toward a higher rate of postpartum temperature greater than or equal to $37.5^{\circ} \mathrm{C}$ in the misoprostol group, from data available, but this did not reach statistical significance (Table 4.4). There were no differences in the modified Labor Agentry Scales between the two groups (by Mann Whitney U test), except for one question. More women in the misoprostol group agreed with the statement "I would prefer to have a medication in the form of a pill rather than an intravenous injection, at the time my baby is delivered." ( $P<0.0001$, Mann Whitney U test). 
Table 4.2.

\begin{tabular}{|c|c|c|c|}
\hline \multicolumn{4}{|l|}{ Postpartum Data } \\
\hline & Oxytocin $\mathbf{n}=76^{\gamma}$ & Misoprostol $\mathbf{n}=80^{\gamma}$ & $\mathbf{P}$ \\
\hline Postpartum Hct.(PCV) & $0.32(0.04)$ & $0.33(0.04)$ & $0.61^{*}$ \\
\hline Postpartum Hct. Change (PCV) & $0.048(0.036)$ & $0.046(0.036)$ & $0.82^{*}$ \\
\hline Estimated blood loss $>500 \mathrm{~mL}$ & 7 & 8 & $0.95^{\circ}$ \\
\hline$H b .<100(g / L)$ & 22 & 19 & $0.43^{\circ}$ \\
\hline Duration stage III (min) & $12.9(17.9)$ & $9.1(8.3)$ & $0.095^{*}$ \\
\hline Additional postpartum oxytocin & 51 & 34 & $0.002^{\infty}$ \\
\hline Postpartum carboprost & & & $0.74^{\circ}$ \\
\hline One dose & 0 & 1 & \\
\hline Two doses & 1 & 0 & \\
\hline Postpartum ergometrine & 0 & 0 & $1.00^{\circ}$ \\
\hline Blood transfusion & 1 & 0 & $0.49^{\circ}$ \\
\hline Manual placental removal & 1 & 1 & $1.00^{\circ}$ \\
\hline Postpartum D\&C & 2 & 0 & $0.24^{\circ}$ \\
\hline
\end{tabular}

'Data given as number or mean (standard deviation)

"Student's t test

"Chi-squared

"Fisher exact test 
Table 4.3.

\begin{tabular}{|l|c|c|c|}
\hline \multicolumn{3}{|c|}{ Side Effects } \\
& Oxytocin & Misoprostol & P \\
& $n=64^{\gamma}$ & $n=58^{\gamma}$ & \\
\hline Nausea & & & $0.37^{\Omega}$ \\
Mild & $8(12.5)$ & $15(25.9)$ & \\
Moderate & $3(4.7)$ & $1(1.7)$ & \\
Vomiting & & & $0.81^{\Omega}$ \\
1-2 episodes & $5(7.8)$ & $5(8.6)$ & \\
$3-4$ episodes & $2(3.1)$ & $0(0)$ & \\
$>4$ episodes & $0(0)$ & $0(0)$ & \\
\hline
\end{tabular}

${ }^{\gamma}$ data given as number (\%)

"Mann Whitney $U$ test 
Table 4.4.

\begin{tabular}{|l|r|r|c|}
\hline \multicolumn{3}{|l|}{ Temperature $\geq 37.5^{\circ} \mathrm{C}$} \\
\hline & Oxytocin $^{\gamma}$ & Misoprostol & P \\
\hline 1hr. postpartum & $6 / 24(25.0)$ & $17 / 34(50.0)$ & $0.055^{\circ}$ \\
4 hr. postpartum & $11 / 53(20.8)$ & $17 / 53(32.1)$ & $0.19^{\infty}$ \\
24hr.postpartum & $2 / 71(2.8)$ & $5 / 76(6.6)$ & $0.44^{\phi}$ \\
\hline
\end{tabular}

Data given as number/sample (\%)

${ }^{\infty}$ Chi-squared test

${ }^{\oplus}$ Fisher exact test 


\section{Chapter 5: DISCUSSION}

\subsection{Discussion of Results}

In this study, there were no significant differences between groups in any blood loss parameters, including change in hematocrit, the primary outcome measure. Except for a trend towards an increase in subsequent postpartum oxytocin use in the oxytocin group, there were no differences in further interventions for excessive blood loss. As the study was not blinded, this intervention was subject to bias. There was also a trend towards a shorter third stage in the misoprostol group, although it did not reach statistical significance. Side effects of nausea and vomiting were not different between the groups.

We began looking at postpartum temperature part way through the study, based upon a report of pyrexia as a side effect of misoprostol (28). Prostaglandin E2 is an ecosanoid known to have a causative role in initiating and sustaining pyrogen induced fever. It is known to act on the pre-optic area of the anterior hypothalamus (39). Prostaglandin E2 also acts at other sites in the brain, but action at these other locations is not well understood (39). The exact mechanism whereby prostaglandin E2 causes temperature elevation is unknown (39). Animal research is ongoing in this area. Misoprostol is known to act as an agonist on prostaglandin E receptors EP1 and EP2 in vivo in the human uterus, as does prostaglandin E2 (26). It is plausible that misoprostol could cause temperature elevation via the same mechanism as prostaglandin E2.

The information on temperature was collected retrospectively on a smaller number of patients, making it impossible to draw definite conclusions based upon this data. Temperatures were similar, except for a trend towards a higher rate of one-hour 
postpartum temperature greater than or equal to $37.5^{\circ} \mathrm{C}$. The highest postpartum temperatures recorded were in the misoprostol group. Two women had temperatures greater than $39^{\circ} \mathrm{C}$. These were $39.4^{\circ} \mathrm{C}$ at two hours and $39.2^{\circ} \mathrm{C}$ at one hour. The first woman had an intrapartum temperature of $38.4^{\circ} \mathrm{C}$ approximately one hour prior to delivery with membranes ruptured greater than 18 hours. However, her temperature then rose to $39.4^{\circ} \mathrm{C}$ after administration of misoprostol. She was treated with intravenous antibiotics for 24 hours. Her temperature dropped to $38.5^{\circ} \mathrm{C}$ at three hours and $37.5^{\circ} \mathrm{C}$ at 24 hours. Thus, her fever was likely due to both infection and misoprostol. The second woman was afebrile at the onset of labour and had no further temperatures recorded until the one-hour measurement of $39.2^{\circ} \mathrm{C}$. However, her labour progressed well with membranes ruptured for just three hours. At two hours postpartum, her temperature had fallen to $38.2^{\circ} \mathrm{C}$ and to $37.4^{\circ} \mathrm{C}$ at 17 hours postpartum. She was treated with intravenous antibiotics for 24 hours and was discharged on oral antibiotics. It is likely that this temperature elevation was a result of the misoprostol. There were two women, also in the misoprostol group, with temperatures greater than $38.5^{\circ} \mathrm{C}$. These were $38.6^{\circ} \mathrm{C}$ and $38.7^{\circ} \mathrm{C}$, both at one hour postpartum. The first woman was afebrile during labour but had no temperature recorded from approximately six hours before delivery until about one hour postpartum. She had rupture of membranes for eight and a half hours. Her temperature elevation had resolved within six hours. Although she was given intravenous antibiotics, because of the rapid resolution of the fever, it was likely due to the misoprostol. The highest temperature recorded for the second woman was $39.3^{\circ} \mathrm{C}$, 
intrapartum after rupture of membranes for six and a half hours. She was treated with intravenous antibiotics intrapartum and one hour after delivery her temperature dropped to $38.7^{\circ} \mathrm{C}$ and $37.5^{\circ} \mathrm{C}$ six hours postpartum. Infection was the likely cause of this woman's temperature elevation. Temperature elevation should not cause serious consequences unless supra physiologic (greater than $41^{\circ} \mathrm{C} 105^{\circ} \mathrm{F}$ ) or prolonged (40). Young women without significant cardiovascular or pulmonary disease should tolerate transient physiologic temperature elevation well. However, there are potentially adverse side effects from antibiotic therapy, which may not be necessary for transient pyrexia in the absence of symptoms or other signs of infection.

Previously, three of the misoprostol third stage trials reported shivering as a remarkable side effect $(27,28,31)$. Two of the trials did not ask about shivering $(29,32)$ or no difference was found between groups (30). One of these studies also found a $0.5^{\circ} \mathrm{C}$ temperature elevation after misoprostol administration to be stastically significant (28).

To determine a dose related side effect profile with respect to temperature and shivering administration of $600 \mu \mathrm{g}$ and $400 \mu \mathrm{g}$ of misoprostol was compared with oxytocin (41). The relative risk of shivering with $600 \mu \mathrm{g}$ of misoprostol was 2.3 (CI 1.55.5) when compared with oxytocin. For misoprostol $400 \mu \mathrm{g}$ compared with oxytocin, the relative risk was 1.54 but the $\mathrm{CI}$ was $0.96-2.44$. With regard to temperature elevation, the relative risk of temperature greater than $38^{\circ} \mathrm{C}$ was 3.7 (CI 1.3-10.9) versus $400 \mu \mathrm{g}$ of misoprostol and 2.5 (CI 1.0-3.6) versus oxytocin. With $400 \mu \mathrm{g}$ of misoprostol an increased risk of temperature elevation was not demonstrated. 
With respect to patient satisfaction, the only significant difference found between groups was that a greater proportion of women preferred to have their medication in the form of a tablet, rather than an injection. This question was one of several questions added to the standard Labour Agentry Scale. The Labour Agentry Scale was designed to measure a woman's sense of control during labour and delivery, as a perception of control was demonstrated to increase tolerance of higher levels of pain and improve functioning on various tasks (38). A woman's perception of control was also correlated with an improved birth experience (38). Thus those women who were given an oral tablet in the third stage would prefer this option again. 


\subsection{Problems}

Recruiting patients in labour is difficult. More patients declined participation than expected. For these reasons, recruitment for this study was much slower than anticipated. The time differential between consent and randomization caused many problems. Randomization had to occur just prior to delivery, to ensure the patient was eligible to participate. Some patients who consented were never randomized, as the time just prior to delivery is very busy and opening randomization envelopes was occasionally forgotten. Ordering the 24-hour postpartum hematocrit and hemoglobin was at times forgotten. Subsequently, twice daily the investigator or research nurse checked the charts of new participants to ensure the 24 hour hematocrit was ordered. Patients receiving the wrong medication also occurred. Administration of oxytocin is the routine; occasionally this was given instead of misoprostol, although data were analyzed on an intent to treat basis. Administration of misoprostol with the anterior shoulder is difficult, and often administration was a short time after this. In summary, the study required the coordinated efforts of many personnel. 


\subsection{Strengths and Weaknesses}

\subsubsection{Validity}

The assignment of patients to the treatment groups was randomized. Tables la and $1 \mathrm{~b}$ illustrated that the groups did appear to be demographically similar at the start of the trial. Although eighteen women did not have data available on postpartum hematocrit change, they were not considered entirely lost to follow up as it is known that none of them had transfusion therapy or a clinical diagnosis of postpartum hemorrhage. The patient data was analyzed on an intent to treat basis, preserving the benefits of the randomization. Recruitment was continued until Hct. data was available for 76 women in the oxytocin group and 80 women in the misoprostol group.

This was not a blinded study, for reasons previously discussed. This does introduce possible bias. Given the primary outcome measure was objective and the personnel involved with measuring hematocrit were blind to patient group assignment, this bias should be reduced. However, a number of the secondary outcomes were not objective measurements made by personnel unaware of group assignment. Therefore, inferences made based upon this data must be viewed with caution, as the possibility of cointervention does exist.

Administration of 5 units of intravenous oxytocin postpartum is the most common

practice at our centre. A small number of attending obstetricians prefers 10 units of oxytocin. We did not restrict the standard treatment to 5 units to prevent nonparticipation of these obstetricians in the study. There may be better efficacy of the 10 unit dose. 
Although fluid retention due to postpartum oxytocin infusion may affect Hct., the administration of postpartum oxytocin was not significantly different between groups 


\subsubsection{Applicability}

The study results are potentially applicable to a very select population. The study sample was taken from a homogenous population of patients at low risk of postpartum hemorrhage. All clinically relevant outcomes were considered with the possible exception of pyrexia, which was added as a secondary outcome once its significance was appreciated. The sample size was not large enough to address significant, but rare outcomes, such as laparotomy and hysterectomy. However, there is no question that the administration of misoprostol instead of oxytocin is both feasible and beneficial to postpartum patients. 


\subsection{Conclusions}

Misoprostol is no less effective than bolus intravenous oxytocin in control of postpartum blood loss in low risk women, with minimal side effects. A blinded randomized controlled trial with objective measurement of the incidence of postpartum hemorrhage as the primary outcome would be more definitive. This could be accomplished in a multi-center trial or in a developing country, where the incidence of postpartum hemorrhage and the birthrate are higher. Investigation of misoprostol use in the third stage should include regular measurements of intrapartum and postpartum temperature to assess the pattern of return to normal temperature and to help differentiate pyrexia caused by misoprostol from pyrexia due to infection. Investigation of optimal oral dose, comparison with rectal misoprostol and prophylactic use in high-risk patients are areas for further study. Ultimately, misoprostol should be investigated for the

treatment of postpartum hemorrhage, where it could be revolutionary in reducing maternal mortality in developing countries. 


\section{REFERENCES}

1. Akins S. Postpartum hemorrhage: A 90s approach to an age-old problem. J of NurseMidwifery 1994;39:123S-34S.

2. Cunningham FG, MacDonald PC, Gant NF, Leveno KJ, Gilstrap LC III. Williams obstetrics. $19^{\text {th }}$ Ed. Norwalk, Connecticut: Appleton \& Lange, 1993.

3. Varnier M. Postpartum Hemorrhage. Critical Care Clinics 1991;7:883-97.

4. Advanced Labour and Risk Management Manual. Society of Obstetricians and Gynecologists of Canada. Postpartum Hemorrhage, 1998.

5. Haththotuwa R, Arulkumaran S, Chua S, Ratnam SS. Postpartum Haemorrhage: Suggestions to Reduce Maternal Mortality and Morbidity. J Indian Med Assoc 1995;93:67-70.

6. Prendville WJ, Harding JE, Elbourne DR, Stirrat GM. The Bristol third stage trial: active versus physiological management of the third stage of labour. Br Med J 1988;297:12951300.

7. Begley CM. A comparison of "active" and "physiological" management of the third stage of labour. Midwifery 1990;6:3-17.

8. Moir DD, Amoa AB. Ergometrine or oxytocin? Blood loss and side-effects at spontaneous vertex delivery. Br J Anaesth 1979;51:113-6.

9. Inch S. Management of the third stage of labour- Another cascade of intervention? Midwifery 1985;1:114-22.

10. O'Brien WF. The role of prostaglandins in labor and delivery. Clin Perinatology 1995;22:973-84. 
11. Calder AA. Review of prostaglandin use in labour induction. Br J Obstet Gynaecol 1997; 104:2S-7S.

12. Reed BD. Postpartum hemorrhage. Am Fam Physician 1988;37:111-120.

13. Popat MT, Suppiah N, White JB. Cardiac arrest following intramyometrial injection of prostaglandin E2. Anaesthesia 1991;46:236.

14. Veber B, Gauthe M, Michel-Cherqui M, des-Menards V, Fischler M. Severe hypertension during postpartum haemorrhage after IV administration of prostaglandin E2. Br J Anaesth 1992;68:623-4.

15. Oleen MA, Mariano JP. Controlling refractory atonic postpartum hemorrhage with Hemabate sterile solution. Am J Obstet Gynecol 1990;162:205-8.

16. Carboprost (Hemabate)- A prostaglandin for postpartum hemorrhage. Drug Ther Bull 1991;29:17-9.

17. Douglas MJ, Duncan FF, Ross PLE, Renwick JE. Cardiovascular collapse following an overdose of prostaglandin F2 $\alpha$ : a case report. Can J Anesth 1989;36:466-9.

18. Hankins GDV, Berryman GK, Scott RT, Hood D. Maternal arterial desaturation with 15 methyl prostaglandin F2 $\alpha$ for uterine atony. Obstet Gynecol 1988;3:367-70.

19. Kerekes L, Domokos N. The effect of prostaglandin F2 $\alpha$ on third stage labour. Prostaglandins 1979; 18:161-6.

20. Poeschmann RP, Doesburg WH, Eskes T. A randomized comparison of oxytocin, sulprostone and placebo in the management of the third stage of labour. $\mathrm{Br} \mathrm{J}$ Obstet Gynaccol 1991;98:528-30. 
21. Van Selm M, Humphrey HH, Kanhai HH, Keirse M. Preventing the recurrence of atonic postpartum hemorrhage: a double-blind trial. Acta Obstet Gynecol Scand 1995;74:270-4 .

22. Devi PK, Sutaria UD, Raghavan KS. Prophylactic use of 15 (S) 15 methyl PGF2 $\alpha$ for control of postpartum bleeding. Acta Obstet Gynecol Scand Suppl 1988;145:7-8.

23. Anjaneyulu R, Devi PK, Jain S, Kanthamani CR, Vijaya R, Raghavan KS. Prophylactic use of $15(\mathrm{~S}) 15$ methyl PGF2 $\alpha$ by intramuscular route-A controlled clinical trial. Acta Obstet Gynecol Scand Suppl 1988;145:9-11.

24. Bhattacharya P, Devi PK, Jain S, Kanthamani CR, Raghavan KS. Prophylactic use of 15(S)15 methyl PGF2 $\alpha$ by intramuscular route for control of postpartum bleeding-a comparative trial with methylergometrine. Acta Obstet Gynecol Scand Suppl 1988;145:13-5.

25. Chua S, et al. A randomized controlled study of prostaglandin 15-methyl F2 $\alpha$ Compared with Syntometrine for prophylactic use in the third stage of labour. Aust NZ J Obstet Gynaecol 1995;35:413-6.

26. Windrim R, Bennett K, Mundle W, Young DC. Oral administration of misoprostol for labour induction: a randomized controlled trial. Obstet Gynecol 1997;89:392-7.

27. Senior JK, Marshall K, Sangha R, Clayton JK. In vitro characterization of prostanoid receptors on human myometrium at term pregnancy. Br J Pharmacol 1993;108:501-6.

28. El-Refaey H, O'Brien P, Morafa W, Walder J, Rodeck C. Misoprostol for third stage of labour. Lancet 1996;347:1257.

29. El-Refaey H, O’Brien P, Morafa W, Walder J, Rodeck C. Use of oral misoprostol in the prevention of postpartum haemorrhage. Br J Obstet Gynaecol 1997;104:336-9. 
30. Bamigboye AA, Merrell DA, Hofmeyr GJ, Mitchell R. Randomized comparison of rectal misoprostol with Syntometrine for management of third stage of labour. Acta Obstet Gynecol Scand 1998;77:178-81.

31. Bamigboye AA, Hofmeyr GJ, Merrell DA. Rectal misoprostol in the prevention of postpartum hemorrhage: a placebo-controlled trial. Am J Obstet Gynecol 1998:179:1043-6.

32. Hofmeyr GJ, Nikodem VC, de Jager M, Gelbart BR. A randomized placebo controlled trial of oral misoprostol in the third stage of labour. Br J Obstet Gynecol 1998;105:9715.

33. O'Brien P, El-Refaey H, Gordon A, Geary M, Rodeck C. Rectally administered misoprostol for the treatment of postpartum hemorrhage unresponsive to oxytocin and ergometrine: a descriptive study. Obstet Gynecol 1998;92:212-4.

34. Djahanbakhch, Vere M, Gardner NHN, Morris EC. The intramuscular use of oxytocic agents for prophylactic management of the third stage of labour. $\mathrm{Br} \mathrm{J}$ Clin Practice $1978 ; 32: 137-8$.

35. ACOG Technical Bulletin/American College of Obstetricians and Gynecologists: Quality assurance in obstetrics and gynecology. Washington, DC, American College of Obstetricians and Gynecologists, 1989.

36. Clarke GL, Douglas CP. A comparison of oxytocic drugs in the third stage of labour. J Obstet Gynaecol Brit Comm 1962;69:904-9.

37. Friedman EA. Comparative clinical evaluation of postpartum oxytocics. Am J Obstet Gynecol 1957;73:1306-1313. 
38. Hodnett ED, Simmons-Tropea DA. The labor agentry scale: psychometric properties of an instrument measuring control during childbirth. Res Nurs Health 1987;10:301-10.

39. Mackowiak PA. Fever: basic mechanisms and management. New York, New York: Raven Press, 1991.

40. Reese RE, Betts RF. A practical approach to infectious diseases. 4th ed. Boston, Massachusetts: Little, Brown and Co., 1996.

41. Lumbiganon P, Hofmeyr J, Gulmezoglu AM, Pinol A, Villar J. Misoprostol dose-related shivering and pyrexia in the third stage of labour. Br J Obstet Gynaecol 1999; 106: 304 8. 


\section{APPENDIX A}

\section{Risk Factors for PPH}

I. Increased risk of uterine atony

a. Uterine overdistention

i. Polyhydramnios

ii. Multiple gestation

iii. Macrosomia

b. Prolonged labour

i. Cesarean delivery

ii. Operative vaginal delivery

c. Precipitate labour

d. Chorioamnionitis

e. Medications

i. Tocolytic agents

ii. Halogenated anesthetic agents

f. High parity

II. Increased risk of genital tract lacerations

a. Operative delivery

i. Forceps or vacuum extraction

ii. Cesarean delivery

b. Episiotomy

c. Macrosomia 
d. Prolonged or precipitate delivery

\section{Increased risk of uterine rupture}

a. Previous uterine surgery

i. Cesarean delivery

ii. Other uterine surgery

b. Other procedures

i. Podalic version

ii. Breech extraction

iii. Midforceps

c. Obstructed labour

d. Abnormal fetal presentation

e. High parity 


\section{APPENDIX B}

\section{MISOPROSTOL VS. OXYTOCIN IN THE THIRD STAGE OF LABOUR IN THE PREVENTION OF POSTPARTUM HEMORRHAGE.}

My intent is to study misoprostol given with delivery of the anterior shoulder in comparison to the standard, in our center, of IV oxytocin after delivery of the placenta, for the prevention of excessive postpartum blood loss. In a chart review of patients delivering in our center, the average drop in hematocrit, in women experiencing vaginal deliveries, is 0.03 .

The benefits of oral misoprostol over oxytocin would include patient acceptance of an oral medication instead of an IV injection, decreased nursing time required to prepare and administer the medication, and decreased cost as no sterile syringe and needle required in administration.

What increase in postpartum blood loss (measured as a drop in hematocrit) would you accept in the misoprostol group to justify its use instead of oxytocin in your patients?

( ) $0.01-0.03$

( ) $0.03-0.06$

( ) $0.06-0.09$ 
( ) other 


\section{LABOUR AGENTRY SCALE:}

1. I felt competent.

$\begin{array}{lllllll}1 & 2 & 3 & 4 & 5 & 6 & 7\end{array}$

AGREE

DISAGREE

2. I was dealing with labour.

$\begin{array}{llllllll}1 & 2 & 3 & 4 & 5 & 6 & 7\end{array}$

AGREE

DISAGREE

3. Everything made sense.

$\begin{array}{lllllll}1 & 2 & 3 & 4 & 5 & 6 & 7\end{array}$

AGREE

DISAGREE

4. I felt very responsible.

$\begin{array}{lllllll}1 & 2 & 3 & 4 & 5 & 6 & 7\end{array}$

AGREE

DISAGREE 
5. I felt incompetent and like I was going to pieces.

$\begin{array}{lllllll}1 & 2 & 3 & 4 & 5 & 6 & 7\end{array}$

AGREE

DISAGREE

6. I felt secure.

$\begin{array}{lllllll}1 & 2 & 3 & 4 & 5 & 6 & 7\end{array}$

AGREE

DISAGREE

7. I felt incapable.

$\begin{array}{lllllll}1 & 2 & 3 & 4 & 5 & 6 & 7\end{array}$

AGREE

DISAGREE

8. I experienced a sense of great anxiety.

$\begin{array}{lllllll}1 & 2 & 3 & 4 & 5 & 6 & 7\end{array}$

AGREE

DISAGREE

9. I felt adequate.

$\begin{array}{llllllll}1 & 2 & 3 & 4 & 5 & 6 & 7\end{array}$

AGREE

DISAGREE 
10. I felt open and receptive.

$\begin{array}{lllllll}1 & 2 & 3 & 4 & 5 & 6 & 7\end{array}$

AGREE

DISAGREE

11. I felt good about my behavior during labour.

$\begin{array}{lllllll}1 & 2 & 3 & 4 & 5 & 6 & 7\end{array}$

AGREE

DISAGREE

12. I felt powerless.

$\begin{array}{llllllll}1 & 2 & 3 & 4 & 5 & 6 & 7\end{array}$

AGREE

DISAGREE

13. I experienced a sense of being with others who care.

$\begin{array}{lllllll}1 & 2 & 3 & 4 & 5 & 6 & 7\end{array}$

AGREE

DISAGREE

14. I didn't know what to expect from one moment to the next.
2
$3 \quad 4$
45
6
7

AGREE

DISAGREE 
15. I experienced complete awareness of everything that was happening.

$$
\begin{array}{lllllll}
1 & 2 & 3 & 4 & 5 & 6 & 7
\end{array}
$$

AGREE

DISAGREE

16. Everything seemed unclear and unreal.

$\begin{array}{lllllll}1 & 2 & 3 & 4 & 5 & 6 & 7\end{array}$

AGREE

DISAGREE

17. I felt relaxed.

$\begin{array}{lllllll}1 & 2 & 3 & 4 & 5 & 6 & 7\end{array}$

AGREE

DISAGREE

18. I experienced a sense of conflict.

$\begin{array}{lllllll}1 & 2 & 3 & 4 & 5 & 6 & 7\end{array}$

AGREE

DISAGREE

19. I felt fearful.

$\begin{array}{lllllll}1 & 2 & 3 & 4 & 5 & 6 & 7\end{array}$

AGREE

DISAGREE 
20. I had a sense of not being in control.

$\begin{array}{lllllll}1 & 2 & 3 & 4 & 5 & 6 & 7\end{array}$

AGREE

DISAGREE

21. I felt important.
12
345
$6 \quad 7$

AGREE

DISAGREE

22. Everything seemed wrong.

$\begin{array}{llllllll}1 & 2 & 3 & 4 & 5 & 6 & 7\end{array}$

AGREE

DISAGREE

23. I felt victorious

$\begin{array}{lllllll}1 & 2 & 3 & 4 & 5 & 6 & 7\end{array}$

AGREE

DISAGREE

24. I experienced a sense of active striving.

$\begin{array}{lllllll}1 & 2 & 3 & 4 & 5 & 6 & 7\end{array}$

AGREE

DISAGREE 
25. I had a feeling of constriction and of being confined.

$\begin{array}{lllllll}1 & 2 & 3 & 4 & 5 & 6 & 7\end{array}$

AGREE

DISAGREE

26. I felt awkward.

$\begin{array}{lllllll}1 & 2 & 3 & 4 & 5 & 6 & 7\end{array}$

AGREE

DISAGREE

27. Someone or something else was in charge of my labour.

$\begin{array}{llllllll}1 & 2 & 3 & 4 & 5 & 6 & 7\end{array}$

AGREE

DISAGREE

28. I experienced a sense of success.

$\begin{array}{lllllll}1 & 2 & 3 & 4 & 5 & 6 & 7\end{array}$

AGREE

DISAGREE

29. I had a sense of perspective on what was happening.

$\begin{array}{lllllll}1 & 2 & 3 & 4 & 5 & 6 & 7\end{array}$

AGREE

DISAGREE 
30. I received explanation regarding the safety and effectiveness of misoprostol.

$\begin{array}{lllllll}1 & 2 & 3 & 4 & 5 & 6 & 7\end{array}$

AGREE

DISAGREE

31. I would recommend the medication I received to a friend if she was having a baby.

$\begin{array}{llllllll}1 & 2 & 3 & 4 & 5 & 6 & 7\end{array}$

AGREE

DISAGREE

32. If I have another delivery, I would be willing to participate in a similar research study.

$\begin{array}{lllllll}1 & 2 & 3 & 4 & 5 & 6 & 7\end{array}$

AGREE

DISAGREE

33. I would prefer to have a medication in the form of a pill, rather than an intravenous injection, at the time my baby is delivered.

$\begin{array}{lllllll}1 & 2 & 3 & 4 & 5 & 6 & 7\end{array}$

AGREE

DISAGREE

34. I experienced nausea after delivery of the baby.

none __ mild ___ moderate __ 
35. I vomited after delivery of the baby.

1-2 times _ 3-4 times __ more than 4 times __

\section{Comments:}




\title{
APPENDIX D
}

CONSENT FORM

\section{MISOPROSTOL VS. OXYTOCIN TO MINIMIZE BLOOD LOSS IN THE THIRD}

\section{STAGE OF LABOUR.}

\section{INVESTIGATORS:}

\author{
Dr. K. Bajzak, Dr. J. Harnett, Dr. J. Crane, Dr. D. Young \\ DESCRIPTION AND BACKGROUND INFORMATION:
}

You are being asked to participate in a research study evaluating two different medications given to minimize blood loss after delivery. Usually, after a baby is born, the mother is given an injection of a medication to help her uterus contract and thereby minimize blood loss. At our centre, the medication used is oxytocin, as an intravenous injection, once the afterbirth has been delivered. Recently, a medication that can be taken by mouth, called misoprostol, has been given to a group of women, instead of the usual medication, to see if it would also minimize blood loss.

In this study, we would like to compare blood loss in women given misoprostol by mouth versus women given an injection of oxytocin.

FORESEEABLE RISKS, DISCOMFORTS, OR INCONVENIENCES:

There will be an additional blood test taken approximately 24 hours after delivery of your baby. You will be asked to fill out a satisfaction questionnaire before you leave the hospital. If the misoprostol is not effective, you may be given additional medications to minimize further blood loss. These medications are given to decrease your risk of excessive blood loss after delivery. 


\section{SIDE EFFECTS:}

Possible side effects of misoprostol include nausea, vomiting and diarrhea. STUDY DESIGN:

If you choose to enter this study, you will be assigned at random (as if by the flip of a coin) to one of two groups. One group will receive misoprostol, by mouth, and the other group will be given an intravenous injection of oxytocin, immediately after the baby has delivered. You will have a blood sample taken in approximately 24 hours to estimate the amount of blood loss you have had. Then your chart will be reviewed, by the investigator, to retrieve the information required. You will remain under the care of your own physician.

\section{ALTERNATIVE TREATMENT:}

If you chose not to enter the study, you will be given the usual treatment of intravenous oxytocin immediately after delivery of your baby.

\section{VOLUNTARY PARTICIPATION:}

You may freely decide not to participate, or to withdraw from the study at any time, without affecting your normal care. You should have discussed the information provided with your physician and he/she should have answered any questions you have regarding your care or treatment.

\section{CONFIDENTIALITY AND ACCESS TO MEDICAL RECORDS:}

You understand that records concerning your labour, delivery and hospital stay will be reviewed, by the investigators or study nurse and you give permission for this. 
No records bearing your name will be provided to anyone other than the investigators in this study. You will not be identified in any publications in any manner.

Your signature on this form indicates that you have understood to your satisfaction the information regarding your participation in the research project and that you agree to participate as a subject. In no way does this waive your legal rights, nor release the investigators, sponsors, or involved institutions from their legal and professional responsibilities.

The investigators will be available should you have any problems or questions regarding the study.

Patient Signature:

Date:

Witness Signature:

Date:

Investigator Signature:

Date: 


\section{APPENDIX E \\ PATIENT INFORMATION SHEET \\ MISOPROSTOL VS. OXYTOCIN TO MINIMIZE BLOOD LOSS IN THE THIRD \\ STAGE OF LABOUR.}

INVESTIGATORS:

Dr. K. Bajzak, Dr. J. Crane.

DESCRIPTION AND BACKGROUND INFORMATION:

You are being asked to participate in a research study evaluating two different medications given to minimize blood loss after delivery. Usually, after a baby is born, the mother is given an injection of a medication to help her uterus contract and thereby minimize blood loss. At our centre, the medication used is oxytocin, as an intravenous injection, once the afterbirth has been delivered. Recently, a medication that can be taken by mouth, called misoprostol, has been given to a group of women, instead of the usual medication, to see if it would also minimize blood loss. In that study, the investigators concluded that the number of women with excessive blood loss, after delivery, in those given the medication by mouth, was similar to the number of women who usually have excessive blood loss that are given the standard medication (an intramuscular injection, similar to oxytocin).

In this study, we would like to see if the medication given by mouth, misoprostol, is effective in minimizing blood loss, as compared with oxytocin.

FORESEEABLE RISKS, DISCOMFORTS, OR INCONVENIENCES: 
There will be an additional blood test taken approximately 24 hours after delivery of your baby. You will be asked to fill out a satisfaction questionnaire before you leave the hospital. If the misoprostol is not effective, you may be given additional medications to help prevent excessive blood loss.

\section{SIDE EFFECTS:}

Possible side effects of misoprostol include nausea, vomiting and diarrhea.

\section{STUDY DESIGN:}

If you choose to enter this study, you will be assigned at random (as if by the flip of a coin) to one of two groups. One group will receive misoprostol, by mouth, and the other group will be given an intravenous injection of oxytocin, immediately after the baby has delivered. You will have a blood sample taken in approximately 24 hours to estimate the amount of blood loss you have had. Then your chart will be reviewed, by the investigator, to retrieve the information required. You will remain under the care of your own physician.

\section{ALTERNATIVE TREATMENT:}

If you chose not to enter the study, you will be given the usual treatment of intravenous oxytocin immediately after delivery of your baby. VOLUNTARY PARTICIPATION:

You may freely decide not to participate, or to withdraw from the study at any time, without affecting your normal care. You should have discussed the information provided with your physician and he/she should have answered any questions you have regarding your care or treatment. 


\section{CONFIDENTIALITY AND ACCESS TO MEDICAL RECORDS:}

You understand that records concerning your labour, delivery and hospital stay will be reviewed, by the investigators or study nurse and you give permission for this. No records bearing your name will be provided to anyone other than the investigators in this study. You will not be identified in any publications in any manner.

Your signature on the consent form indicates that you have understood to your satisfaction the information regarding your participation in the research project and that you agree to participate as a subject. In no way does this waive your legal rights, nor release the investigators, sponsors, or involved institutions from their legal and professional responsibilities.

The investigators will be available should you have any problems or questions regarding the study. 


\section{APPENDIX F}

\section{DATA COLLECTION SHEET}

\begin{tabular}{|l|}
\hline Chart \# : \\
\hline Group \\
\hline Age \\
\hline Gravidity \\
\hline Parity $\quad$ ( ) no \\
\hline Oxytocin: $\quad$ yes \\
\hline induction ( ) \\
i) start time \\
ii) delivery time \\
Post-Delivery Het. \\
augmentation ( ) \\
\hline i) start time \\
ii) delivery time \\
\hline
\end{tabular}


Further Administration of: (specify amount and number of doses)

- Oxytocin ( )

i) bolus ( )

ii) infusion ( )

- $\quad$ Ergot ( )

- Hemabate ( )

- Other ( )

Clinical dx of pph ( ) yes ( ) no

Estimated blood loss ce

Operative Intervention ( ) yes ( ) no

- manual placental removal ( )

- d \& c ( )

- laparotomy ( )

- hysterectomy ( )

Transfusion ( ) yes ( ) no 


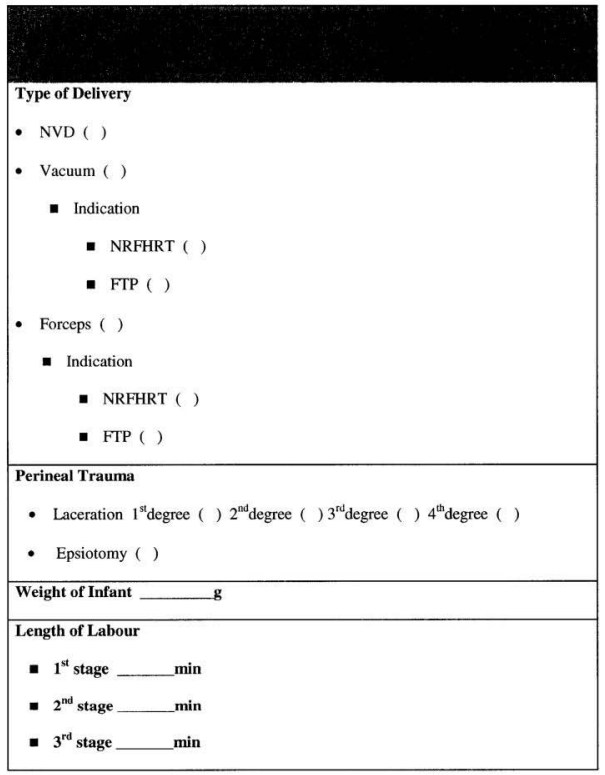





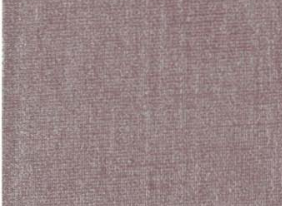

(5)

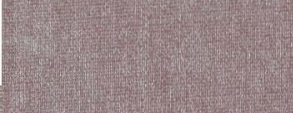

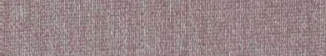
15. W

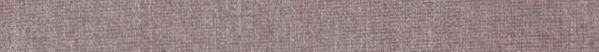

